\title{
Avaliação da percepçáo sobre o ambiente de circulaçáo: a acessibilidade centrada no usuário ${ }^{1}$
}

\author{
Éden Fernando Batista Ferreira ${ }^{a}$, Otavio Augusto de Araujo Costa Folha ${ }^{b}$, \\ Maisa Sales Gama Tobias ${ }^{c}$

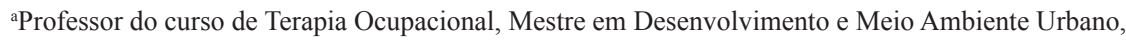 \\ Universidade da Amazônia - UNAMA, Belém, PA, Brasil

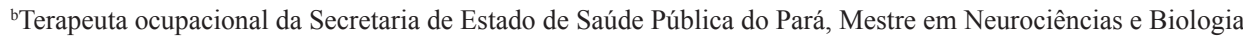 \\ Celular pela Universidade Federal do Pará - UFPA, Belém, PA, Brasil \\ 'Professora titular da Universidade da Amazônia - UNAMA, Doutora em Engenharia de Transportes pela \\ Universidade de São Paulo - USP, São Paulo, SP, Brasil
}

\begin{abstract}
Resumo: A discussão sobre a acessibilidade em ambientes urbanos é observada em diversos estudos, porém a grande maioria centra a atenção nos elementos estruturais e não no usuário. Este estudo apresenta uma proposta de método de avaliação do ambiente urbano de circulação do ponto de vista de seus usuários, para identificar o relacionamento entre a percepção de barreiras e facilitadores presentes no ambiente de circulação e os aspectos ligados às funções e estruturas do corpo e à participação dos usuários em atividades, o que denota o grau de acessibilidade dessas pessoas no ambiente. O trabalho retrata um estudo de caso em Belém, Pará. Utiliza um método de avaliação da percepção dos usuários baseado nos indicadores de fatores ambientais, atividade e participação e estrutura e funções do corpo elencados pela Classificação Internacional de Funcionalidade Incapacidade e Saúde - CIF. O principal achado deste estudo indica que a percepção das pessoas sobre o seu ambiente de circulação influencia diretamente o envolvimento em suas ocupações. Estudos com esse teor são pertinentes e necessários em nossa sociedade, pois revelam de que forma as mudanças nos grandes centros urbanos influenciam a acessibilidade e o envolvimento das pessoas em suas ocupações, interferindo diretamente na sua saúde, na qualidade do viver e na sua participação na sociedade.
\end{abstract}

Palavras-chave: Percepção Ambiente, Tecnologia Assistiva, Classificação Internacional de Funcionalidade, Incapacidade e Saúde, Estruturas de Acesso.

\section{Evaluation of perception on environmental movement: accessibility centered in the user}

\begin{abstract}
Introduction: The discussion about accessibility in urban environments is observed in several studies, but the vast majority focuses attention on structural elements and not the user. Objective: This study proposes a method of assessing urban environmental movement, from the point of view of its users, to identify the relationship between perceived barriers and facilitators in the environment movement and aspects of the body functions and structures and the users' participation in activities, which denotes the degree of accessibility of these people in this space. Method: It describes a case study in Belem, Para state, utilizing a method of assessing the perception of users, based on indicators of environmental factors, activity and participation, structure and functions of the body, highlighted by the International Classification of Functioning, Disability and Health - ICF. Results: The main finding of this study indicates that people's perceptions about their environment directly influences the
\end{abstract}

Autor para correspondência: Éden Fernando Batista Ferreira, Universidade da Amazônia, Campus Alcindo Cacela, 287, CEP 66060-902, Belém, PA, Brasil, e-mail: to.eden.ta@hotmail.com

Recebido em 5/12/2012; Aceito em 10/1/2013. 
movement involved in their occupations. Conclusion: Studies with this content are relevant and necessary in our current society, because they reveal how changes in major urban centers influence the accessibility and involvement of people in their occupations, thereby directly interfering with their health, quality of life, and participation in society.

Keywords: Perception; Environment, Self-help Devices, International Classification of Functioning, Disability and Health, Architectural Accessibility.

\section{Introdução}

O ser humano é, em essência, ocupacional (WILCOCK, 1993), ou seja, estrutura e organiza seu cotidiano através do envolvimento em ocupações. Essas ocupaçôes são as coisas rotineiras e familiares que as pessoas fazem todos os dias, como tomar banho, almoçar, estudar, trabalhar, cuidar dos filhos etc., sendo pessoais e culturalmente significativas (CLARK; LAWLOR, 2009; CLARK; ZEMKE, 1996). Essas açóes possuem formas, ou seja, aspectos diretamente observáveis, apresentam sentidos, em virtude de proporcionarem condiçóes de existência, saúde, qualidade de vida e participação social às pessoas, bem como desvelam significados no contexto da vida dessas pessoas (CLARK; WOODY; LARSON, 2002).

Entre as ocupaçôes desenvolvidas no cotidiano estão as atividades instrumentais de vida diária, ações que demandam uma complexidade maior de interaçôes entre o sujeito que as desempenha e o ambiente no qual elas ocorrem (AMERICAN..., 2008; CAZEIRO et al., 2011). Um exemplo dessas ocupaçôes é a mobilidade na comunidade, que inclui a utilizaçáo de transporte privado ou público, tais como dirigir, caminhar, andar de bicicleta, usar um transporte coletivo, entre outras (AMERICAN..., 2008). A legislação brasileira considera como direito fundamental do cidadão o ir e vir (BRASIL, 1988). Sendo assim, cabe aos gestores de políticas e programas o gerenciamento e a implementação de estratégias de acessibilidade e inclusão (CAVALCANTI; GALVÃO; MIRANDA, 2007) no intuito de equiparar oportunidades e dar condiçôes para que as pessoas possam desempenhar suas ocupaçôes.

Nos últimos anos, no Brasil, observamos o crescimento de políticas e programas que visam assegurar que as pessoas tenham oportunidades de desenvolver da forma mais independente e autônoma possível suas ocupaçôes (BRASIL, 2011). Para alcançar esse objetivo, entre as estratégias utilizadas está o desenvolvimento de tecnologias assistivas, produtos e serviços que auxiliam no desempenho de ocupaçóes, ajudam a compensar limitaçóes funcionais e facilitam uma vida independente (MELLO, 2008), bem como a melhoria nas condiçóes de acessibilidade, entendida como possibilidade e condição de alcance, percepção e entendimento para a utilizaçáo com segurança e autonomia dos espaços e equipamentos (ASSOCIAÇÃO..., 2004). Isso inclui $\mathrm{o}$ acesso das pessoas a escolas, teatros, hospitais e depende significativamente da acessibilidade arquitetônica do meio (CAVALCANTI; GALVÃO; MIRANDA, 2007).

$\mathrm{Na}$ perspectiva da acessibilidade, o ambiente urbano é analisado sob a óptica da infraestrutura viária, condiçôes e adequaçáo às modalidades de transportes, dentre outros aspectos. A interação dos deslocamentos de pessoas e bens com a cidade é o que configura a mobilidade urbana (ALBANO, 2006). A cidade pode ser entendida como um conjunto numeroso de estruturas físicas destinadas a sustentar o processo de desenvolvimento. Esse ambiente não é estático e está sujeito a um processo constante de construção e destruiçáo, em meio a processos econômicos complexos. Em cada cidade se materializa um sistema espacial complexo, que compreende uma montagem interdependente de áreas funcionais, as quais são denominadas estruturas de produção, reprodução e circulação (VASCONCELLOS, 2011).

A estrutura de circulação refere-se, portanto, à parte do ambiente construído que permite a circulação física de pessoas e mercadorias: vias públicas, calçadas, vias férreas e terminais de passageiros e cargas. $\mathrm{Na}$ estrutura de circulaçáo tem-se o suporte físico da circulação propriamente dita, seja a pé ou utilizando qualquer outro modo de transporte, o que é denominado meios de circulação (VASCONCELLOS, 2011).

Porém, com o crescimento das cidades, as vias sofrem sobrecarga de fluxo de pessoas e cargas, gerando conflitos entre os usuários e repercutindo no padráo de viagens das pessoas, podendo haver limitações de acessibilidade. O impedimento ou a dificuldade em realizar plenamente as ocupaçôes que compóem o cotidiano das pessoas pode repercutir diretamente em suas condiçôes de saúde, na sua 
qualidade do viver e na sua participação na sociedade (LAW; STEINWENDER; LECLAIR, 1998).

Pressupomos que a percepção dos usuários sobre o ambiente de circulação tem relação direta com as condiçóes de capacidade e funcionalidade. Isso está baseado em estudos que demonstram que o comportamento dos usuários no espaço de circulação é influenciado por estímulos ambientais presentes nas vias (ROZESTRATEN, 1988; SILVA; EGLER, 2002). Não obstante entendermos que existem fatores intrínsecos que influenciam no comportamento do usuário do ambiente de circulação, os quais acreditamos estarem relacionados à funcionalidade, capacidade e saúde do ser humano.

Nesse contexto, entendemos que a percepçáo do ambiente está relacionada diretamente às formas, aos sentidos e aos significados com os quais a ocupaçóes são desempenhadas. Barber e Legge (1976) definiram percepção como o "processo de recepção, seleção, aquisiçáo, transformação e organização das informaçōes fornecidas por nossos sentidos". Esses autores consideraram que a percepção é a porta de entrada para toda a informação que a pessoa recebe e processa, sendo também um aspecto importante a considerar nos estudos de avaliação, pois através da percepçáo do indivíduo podemos vislumbrar o desenvolvimento de sistemas de transporte mais adequados às suas necessidades, do ponto de vista daquilo que é melhor para o usuário diante das suas limitaçôes físicas e emocionais.

Outros estudos relacionados à percepção demonstram que é possível desenvolver uma melhor compreensão sobre as interrelaçóes entre o homem e o meio ambiente, suas expectativas, julgamentos e condutas, além disso, estudos com esse teor podem revelar ideias e impressóes que os grupos têm sobre algo, considerando que possuem necessidades, valores, interesses e expectativas (RIO; OLIVEIRA, 1996; SILVA; EGLER, 2002).

Ao mesmo tempo observamos nos últimos anos a ampliação da compreensão dos fatores que influenciam a saúde e a qualidade do viver das pessoas. Nessa perspectiva, destacamos a Classificação Internacional de Funcionalidade, Incapacidade e Saúde - CIF da Organização Mundial de Saúde em 2001 (ORGANIZAÇÃO..., 2003), a qual descreve funcionalidade e incapacidade relacionadas às condiçôes de saúde, a partir das condiçôes das funçóes e estruturas do corpo, assim como das condiçóes de engajamento em atividades sociais no meio ambiente em que a pessoa vive (FARIAS; BUCHALLA, 2005). A CIF é baseada numa abordagem biopsicossocial que incorpora os componentes nos níveis corporais e sociais. Trata-se de uma evoluçáo do modelo biomédico, baseado em diagnósticos, para um modelo que incorpora três dimensôes: a biomédica, a psicológica e a social, e onde cada nível age sobre e sofre a ação dos demais, sendo todos influenciados pelos fatores ambientais (ORGANIZAÇÃO..., 2008).

Para o contexto cidade, a CIF apresenta os fatores ambientais como um dos componentes de análise, considerando-os como fator de impacto direto sobre todos os componentes de funcionalidade e incapacidade. Isso quer dizer que mesmo com condiçóes de funçóes e de estruturas do corpo preservadas e sem alteraçóes, fatores ambientais ainda podem comprometer o engajamento em ocupaçóes cotidianas. Por este motivo, a OMS (ORGANIZAÇÃO..., 2002) considera que a CIF, socialmente, tem entre suas aplicações as avaliaçóes de projetos arquitetônicos universais e, dentre os aspectos abordados, a acessibilidade, a identificação de facilitadores e barreiras e as mudanças de políticas sociais.

Portanto, neste trabalho entendemos que a avaliação de um projeto de urbanização deve permitir identificar se as estratégias, recursos e equipamentos utilizados atendem as necessidades dos usuários em relação à sua capacidade de participação em ocupaçōes ou suas dificuldades e deficiências de funcionalidade. O que observamos na maioria dos instrumentos de pesquisa presentes nos estudos sobre esse tema é a carência de associação específica para a avaliação da relação existente entre o ambiente de circulaçáo, a funcionalidade e a capacidade dos usuários no espaço de circulação.

\section{Objetivos}

Avaliar a percepção dos usuários sobre fatores ambientais que influenciam na circulação urbana utilizando os domínios e categorias descritos na CIF como referência para a proposição de um método que associe a avaliação da percepção que o usuário tem do ambiente de circulação em que vive às suas características de funcionalidade e capacidade, diante de fatores ambientais, e avaliar, igualmente, no que isso pode influenciar na mobilidade urbana, ou seja, em suas ocupaçóes cotidianas.

\section{Método}

\subsection{Local}

Realizamos um estudo de caso no município de Belém do Pará, localizado na região Norte do Brasil, com população estimada de 1.393.399 
habitantes (INSTITUTO..., 2012). Optamos por essa cidade pois, recentemente, diversas intervençôes de urbanização nos espaços de circulação têm sido nela implementadas, com iniciativas voltadas para tornar as vias cada vez mais acessíveis aos seus usuários, através do uso de novos tipos de pavimento, incorporação de ciclovias aos novos projetos, ampliação das áreas de lazer no espaço público, dentre outras. Essas modificaçôes estruturais do ambiente de trânsito geram impactos na mobilidade dos seus usuários que nem sempre podem ser qualificados ou quantificados pelos instrumentos tradicionais de pesquisa sobre a estrutura física da via, considerando que a percepção de incremento de qualidade de vida, em função das mudanças estruturais ocorridas no espaço público, está relacionada à percepção dos envolvidos sobre o ambiente de circulação, de si mesmos e das atividades que desenvolvem.

Para aplicação da avaliação escolhemos a avenida Marquês de Herval (Figura 1). Essa avenida foi escolhida por ter sido um espaço recente de transformação urbanística, com implantação de projeto de sinalizaçáo e revisão do projeto viário, incorporando espaço de lazer e de uso exclusivo para bicicletas e caminhadas.

\subsection{Participantes e aspectos éticos}

A pesquisa de campo para a aplicação do questionário teve como universo 600 lotes residenciais (COMPANHIA..., 2000), excluindo-se lotes comerciais ou desocupados. Assim, para um intervalo de confiança de $90 \%$ e um erro admissível de $10 \%$, utilizando uma amostragem probabilística populacional, obtivemos tamanho da amostra de 60 residências a serem visitadas, sendo um entrevistado por domicílio. A pesquisa ocorreu durante um mês, em dois turnos do dia. Para cada domićlio foi entrevistado um residente maior de 18 anos em condições de expressar suas opinióes. A escolha da residência seguiu

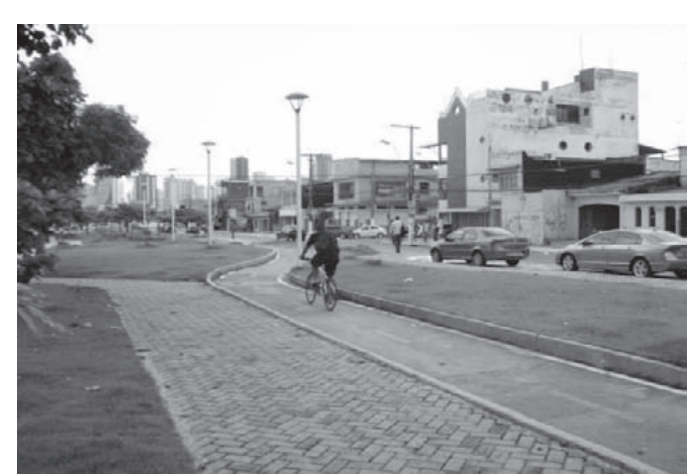

Figura 1. Imagens da avenida Marques de Herval, Belém, Pará. uma ordem aleatória, porém buscando cobrir toda a extensão da via. Os participantes foram escolhidos aleatoriamente, não havendo restrição quanto ao grau de mobilidade das pessoas, ou mesmo em função de algum problema físico ou mental. Quanto aos preceitos éticos, esta pesquisa foi aprovada pelo Comitê de Ética em Pesquisa em Seres Humanos da Universidade da Amazônia.

\subsection{Instrumentos de coleta de dados}

Baseamos a elaboração do método de avaliação da percepção do ambiente de circulação na proposição de três componentes da classificação CIF para identificar o nível de funcionalidade e capacidade das pessoas (fatores ambientais, atividade e participação e funçōes e estruturas do corpo). O método de avaliação proposto procurou evidenciar como o usuário percebe seu ambiente de circulação e percebe a si mesmo em relação a possíveis dificuldades ou deficiências.

A categoria de Fatores ambientais envolveu domínios como produtos e tecnologia, onde estão os componentes usados em projetos, arquitetura e construção e, ainda, domínios de desenvolvimento da zona urbana. Os domínios e componentes dessa categoria foram organizados da seguinte forma: Produtos e tecnologias: componentes usados em projetos, arquitetura e construçâo para entrada e saída de edifícios de uso público e do desenvolvimento urbano; Ambiente natural e mudanças ambientais feitas pelo ser humano: geografia física - formas de terreno; população: mudanças demográficas e densidade populacional; flora e fauna: plantas e animais; clima: temperatura, umidade, chuvas, ventos e variação sazonal; luz; som e qualidade do ar; e Serviços, sistemas e políticas: serviços, sistemas e políticas de arquitetura e construção; serviços, sistemas e políticas de planejamento de espaços abertos; serviços, sistemas e políticas dos serviços públicos; e serviços, sistemas e políticas de transporte.

Para a categoria Atividade e participaçáo foram utilizados domínios e respectivos componentes relacionados às capacidades e habilidades aprendidas e utilizadas diretamente no ambiente de circulação e a elementos que geram motivação para o deslocamento; Aprendizagem e aplicaçáo de conhecimentos: capacidade para ler, para escrever, calcular, resolver problemas, tomar decisões; Tarefas e demandas gerais: capacidade de realizar rotinas diárias; Comunicação: habilidade de conversação; Mobilidade: capacidade de mudar a posição básica do corpo, manter a posição do corpo, percorrer diferentes distâncias andando, deslocar-se por diferentes locais, deslocar-se utilizando algum equipamento, utilizar transportes e dirigir; Âreas 
principais da vida: habilidades relacionadas à educação, trabalho e emprego; Vida comunitária, social e cívica: habilidades relacionadas à recreação, religião e espiritualidade, vida política e cidadania.

$\mathrm{Na}$ categoria Funçóes e estruturas do corpo, os domínios foram selecionados para compor o instrumento de avaliação de critérios relacionados às funçôes e estruturas que permitem ao usuário imprimir sua percepção e às funçôes e estruturas básicas para deslocamento e mobilidade: Funçóes mentais: envolvem funções de orientação, memória, cognição, atenção, energia e impulsos; Funçóes sensoriais e dor: funçôes sensoriais de visão, auditiva e vestibular; Funçóes de voz e fala: produção e qualidade da voz; Funçóes neuromusculoesqueléticas e relacionadas ao movimento: integridade funcional das articulaçôes e da força muscular; Estruturas relacionadas ao movimento: estrutura óssea e estrutura ligamentar.

Portanto, cada componente e domínio selecionado para compor o instrumento de avaliação foi organizado em um questionário composto por perguntas fechadas, com as questóes sistematizadas no formato da escala de Likert (1932) de tal forma que os entrevistados puderam avaliar cada item de acordo com sua percepção. Para os fatores ambientais, os entrevistados classificaram, primeiramente, cada domínio/componente questionado como uma barreira ou facilitador. Em seguida, para cada item, avaliado como barreira ou facilitador, classificando-os de 0 a 4, na ordem de menor barreira ou facilitador a barreira ou facilitador completo. Em relação às categorias atividade e participação e funçóes e estruturas do corpo, quantificaram sua percepçáo em relação às dificuldades ou deficiências a cada item questionado, de 0 a 4 , na ordem de nenhuma dificuldade a dificuldade completa.

O resultado da avaliação da percepçáo dos usuários sobre o ambiente de circulação foi obtido pela soma das frequências das respostas por item de cada domínio do questionário multiplicado pelo peso atribuído por qualificador $(0,1,2,3$ ou 4). Destacamos que foi possível uma diferença entre o máximo que cada item poderia obter, ou seja, o valor ideal (com nota 4 e 100\% da pontuação possível), e o máximo a ser obtido das respostas, ou seja, o valor real. Esse valor foi convertido em percentual por meio de um cálculo proporcional entre ele e a pontuação que recebeu (Quadro 1).

\section{Resultados e discussão}

$\mathrm{Na}$ Tabela 1 estão os dados obtidos com a aplicação do modelo de avaliação nas pontuaçóes atribuídas nas respostas, as quais permitiram avaliar o grau de satisfação com o projeto urbanístico implantado. Os percentuais das categorias de análise indicaram que a população, em geral, identifica os elementos do ambiente de circulação como barreiras e facilitadores moderados, determinando o projeto como satisfatório.

\subsection{Fatores ambientais}

Os principais fatores referidos como barreira pela população entrevistada, 26, estáo relacionados a condiçôes ambientais e representam $4 \%$ da percepção dominante (Tabela 1). A temperatura, a umidade, a chuva e a variação sazonal são elementos influenciados, em grande parte, pela característica climática da regiâo norte do Brasil. A alta temperatura associada a chuvas quase diárias, influenciada pela umidade e pela variação sazonal são elementos que, na percepção dos usuários da via, comprometem a circulação. Nas Figuras 2 e 3 apresentamos os resultados em relação à percepção do clima, da qualidade do ar e do som na via, apontados como barreira pelos usuários.

A qualidade do ar e o som na via podem ser considerados consequência negativa da própria

Quadro 1. Intervalos de pontuação atribuída por qualificador.

\begin{tabular}{|l|c|c|c|c|}
\hline \multicolumn{1}{|c|}{ Barreira } & Facilitador & $\begin{array}{c}\text { Funções e estruturas } \\
\text { do corpo }\end{array}$ & $\begin{array}{c}\text { Atividade e } \\
\text { participação }\end{array}$ & $\begin{array}{c}\text { Pontuação } \\
\text { atribuída em \% }\end{array}$ \\
\hline Nenhuma barreira & Nenhum facilitador & $\begin{array}{c}\text { Nenhuma dificuldade } \\
\text { ou deficiência }\end{array}$ & Nenhuma dificuldade & $0-4$ \\
\hline Barreira leve & Facilitador leve & $\begin{array}{c}\text { Dificuldade ou } \\
\text { deficiência leve }\end{array}$ & Dificuldade leve & $5-24$ \\
\hline Barreira moderada & $\begin{array}{c}\text { Facilitador } \\
\text { moderado }\end{array}$ & $\begin{array}{c}\text { Dificuldade ou } \\
\text { deficiência moderada }\end{array}$ & Dificuldade moderada & $25-49$ \\
\hline Barreira grave & $\begin{array}{c}\text { Facilitador } \\
\text { considerável }\end{array}$ & $\begin{array}{c}\text { Dificuldade ou } \\
\text { deficiência grave }\end{array}$ & Dificuldade grave & $50-95$ \\
\hline Barreira completa & $\begin{array}{c}\text { Facilitador } \\
\text { completo }\end{array}$ & $\begin{array}{c}\text { Nenhuma dificuldade } \\
\text { ou deficiência }\end{array}$ & Dificuldade completa & $96-100$ \\
\hline
\end{tabular}


Tabela 1. Resultados das pontuações atribuídas por categoria e qualificador.

\begin{tabular}{lcl}
\hline \multicolumn{1}{c}{ Categoria } & Percepção dominante em \% & \multicolumn{1}{c}{ Qualificador } \\
\hline Fatores ambientais - barreiras & 26,4 & Barreira moderada \\
Fatores ambientais - facilitadores & 32,1 & Facilitador moderado \\
Atividades e participação & 19,7 & Dificuldade leve \\
Funções e estruturas do corpo & 12,1 & Dificuldade ou deficiência leve \\
\hline
\end{tabular}

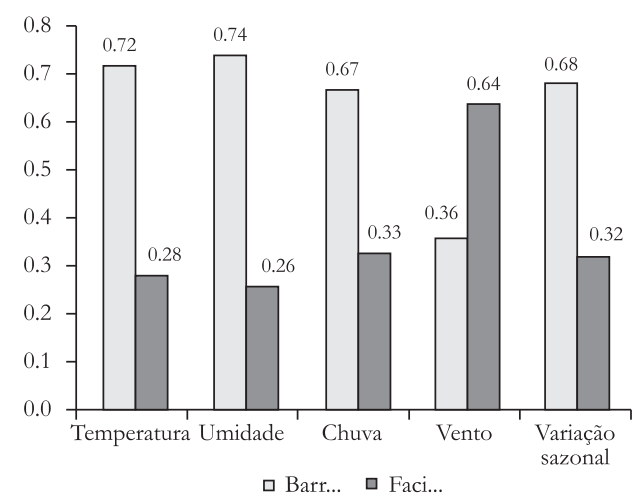

Figura 2. Percepção da influência do clima.

reforma realizada na via pois, com as modificações, a avenida Marquês de Herval, que sempre foi um importante corredor de tráfego da cidade, aumentou a atração de viagens. Por sua vez, o aumento do tráfego elevou o índice de ruído, bem como a emissão de gases que comprometem a qualidade do ar. Os serviços, sistemas e políticas de transporte, entendidos como serviços e programas voltados para o deslocamento de pessoas ou mercadorias por meio de transporte público ou privado, incluindo aqueles que prestam serviços, foram outro elemento dos fatores ambientais percebido como barreira (57\%). As modificaçóes realizadas nesse sentido referem-se, principalmente, à colocação de ciclovias e adequação de vagas para estacionamento no canteiro central. No que diz respeito à qualidade do serviço e à relação entre oferta e demanda, o transporte público recebe queixas frequentes.

Apesar dessas percepçóes que, em parte, não aprovaram as alteraçóes urbanísticas realizadas na av. Marquês de Herval, a maioria dos elementos aplicados no instrumento de avaliação foram percebidos positivamente pelos entrevistados. Inclusive elementos que poderiam ser questionados, como barreiras, o aumento de densidade populacional, o aumento do número de pessoas que transitam e residem ao longo $\mathrm{da}$ via e que poderiam interferir no deslocamento, o que não foi percebido dessa maneira pela população, sendo esse item avaliado como facilitador pela grande maioria dos entrevistados. As obras de arquitetura e construçáo, como nivelamento das calçadas, a prestaçáo de serviços públicos como coleta de

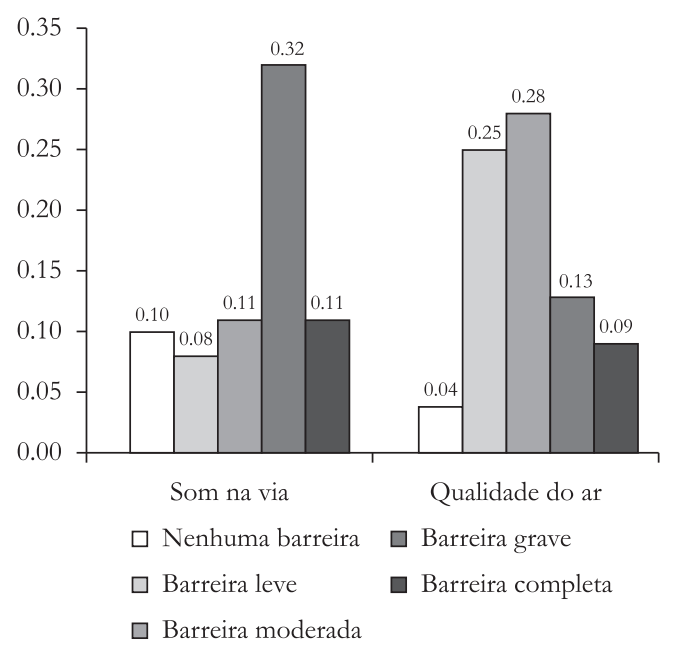

Figura 3. Percepção de sons e qualidade do ar.

lixo e o planejamento dos espaços que envolvem a implantação de academias ao ar livre e de playgrounds foram elementos avaliados positivamente pela maioria dos entrevistados. Esses elementos, além de favorecerem a circulação na via, garantindo a acessibilidade, também têm uma função social, porque contribuem para as relaçóes sociais por meio dos espaços de convivência.

\subsection{Fatores ligados a atividades e participação}

Os resultados relacionados com a categoria atividade e participação (Tabela 1) determinaram dificuldade leve em relação ao engajamento e em atividades e participação das pessoas. Entretanto, há resultados em relação à aprendizagem e aplicação do conhecimento em que se identificou que $49 \%$ das pessoas relataram ter dificuldades em atividades como ler, escrever ou calcular, elementos que influenciam na aprendizagem prévia de sinais e das normas que devem ser seguidas no ambiente de circulação. Resultado semelhante foi identificado em relação à mobilidade: pde-se observar que mais de $60 \%$ dos entrevistados não se referiram às dificuldades mas a questôes diretamente relacionadas ao deslocamento no ambiente de circulação, como a capacidade de andar e de utilizar transporte, a qual foi possível 
identificar em uma parcela significativa da população representada por mais de $50 \%$ dos entrevistados, os quais referiram ter dificuldades.

\subsection{Fatores ligados a funções e estruturas do corpo}

O foco da pesquisa não foi em pessoas com deficiência previamente identificada, por isso o resultado apresentado na Tabela 1 aponta a percepção geral dos entrevistados dessa dificuldade como dificuldade ou deficiência leve. Entretanto, na análise dos dados apresentada na Figura 4 é possível identificar que as deficiências, mesmo que consideradas leves, estấo presentes. Um aspecto importante que o modelo de avaliaçáo permitiu constatar é que a percepção de barreiras nos Fatores ambientais nem sempre está condicionada a dificuldades ou deficiências identificadas em relação a funçōes e estruturas do corpo ou a atividade e participaçáo - $60 \%$ dos entrevistados afirmaram ter nenhuma dificuldade ou dificuldade leve em relação ao acesso aos sistemas de transporte público.

Esta pesquisa gerou resultados que permitiram construir um entendimento sobre como a população de uma regiáo que passou por um processo de urbanizaçăo percebe esse ambiente, bem como como ela se relaciona com sua capacidade de engajamento em atividades diárias ou com as dificuldades relacionadas a funçóes e estruturas do corpo. A proposta do modelo, inspirado na utilização de categorias da CIF, permitiu analisar não só o ambiente físico relacionado à mobilidade, como também analisar como as pessoas se veem dentro desse ambiente a partir da avaliação que fazem de sua saúde, capacidade e funcionalidade.

Constatamos que o entendimento que as pessoas constroem sobre o espaço de circulação em relação a barreiras ou facilitadores não é determinado por

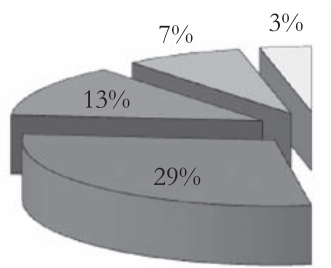

Nenhuma dificuldade - $48 \%$ $\square$ Dificuldade leve - $29 \%$

$\square$ Dificuldade moderada - $13 \%$

Figura 4. Percepção das funções e estruturas do corpo. dificuldades que se interpóem ao seu desempenho para desenvolver açóes, como deslocar-se em terrenos irregulares, ou por considerarem que apresentam algum tipo de deficiência motora. Muitos entrevistados, cerca de $40 \%$, que se consideraram em termos de funçôes e estrutura do corpo como sem dificuldades ou com dificuldades leves, avaliaram os fatores relacionados com o ambiente de circulaçâo como barreira grave. Esse resultado revela que o ambiente de circulação pode ser um fator limitante em relação à acessibilidade, inclusive para pessoas sem deficiência diagnosticada ou determinada.

A identificação de itens no domínio das políticas de arquitetura e construção, serviços de transporte, qualidade da iluminação da via, entre outros, como barreiras consideráveis de acessibilidade, refletem o descontentamento da população com o atual processo de urbanização, apesar de, no âmbito geral, projetos de reurbanização como o da avenida Marquês de Herval serem bem percebidos positivamente como avanço nas condiçóes de acessibilidade aos espaços públicos urbanos.

Esses resultados nos remetem a algumas indagações e reflexôes: Qual o impacto do processo de urbanização sobre o engajamento das pessoas em sua ocupação? De que forma essas ocupações podem ser desempenhadas? Qual o impacto dos ambientes de circulação sobre a saúde, a qualidade do viver e a participação social das pessoas? Nas metrópoles, como Belém, qual o impacto do congestionamento no trânsito, da carência de acessibilidade, entre outros aspectos, sobre o envolvimento dos cidadãos em suas ocupaçóes? Como eles se adaptam? Tais perguntas requerem respostas quantitativas e qualitativas e suscitam estudos posteriores.

\section{Conclusões}

O método proposto permitiu a avaliação do espaço público de circulação, estabelecendo relaçóes entre a percepção dos fatores ambientais e a percepçáo de funcionalidade e incapacidade dos usuários e contribuindo para a discussão da análise de acessibilidade em função das características dos usuários. O método permite análises individuais dos fatores, assim como uma análise global da interação entre os fatores, servindo a outras situaçôes de análise de acessibilidade em espaços públicos urbanos. Dada a aplicação da estrutura geral do método e o teste efetuado no estudo de caso, podemos dizer que a análise é válida para ambientes onde intervençóes recentes foram realizadas, podendo não se aplicar a ambientes já consolidados onde o próprio indivíduo pode ter perdido a sensibilidade 
às mudanças implementadas, ou mesmo gerar percepçóes muito diferentes sobre determinados domínios, por já estarem acostumados ao fato.

Acreditamos que estudos com esse teor são pertinentes e necessários em nossa sociedade, pois revelam de que forma as mudanças nos grandes centros urbanos influenciam o envolvimento das pessoas em suas ocupaçôes, interferindo diretamente na sua saúde, na qualidade do viver e em sua participação na sociedade.

\section{Referências}

ASSOCIAÇÃO BRASILEIRA DE NORMAS TÉCNICAS - ABNT. NBR 9050: acessibilidade a edificaçôes, mobiliário, espaços e equipamentos urbanos. Rio de Janeiro: ABNT, 2004.

ALBANO, J. J. Circulação e Mobilidade Urbana. Porto Alegre: LASTRAN; URFGs, 2006. Disponível em: <http://www.producao.ufrgs.br/arquivos/ disciplinas/494_15_1mobilidade_aspectos_ conceituais_\%5Bmodo_de_compatibilidade\%5D.pdf>. Acesso: 22 out 2010.

AMERICAN OCCUPATIONAL THERAPY ASSOCIATION - AOTA. Framework Occupational Therapy Practice: Domain and Process. 2ed. American Journal of Occupational Therapy, New York, v. 62, n. 6, p. 625-683, 2008.

BARBER, P. J.; LEGGE, D. Informação e Habilidade. Rio de Janeiro: Zahar, 1976.

BRASIL. Constituição (1988). Constituição da República Federativa do Brasil. Brasília: Senado Federal, 1988.

BRASIL. Casa Civil. Decreto no 7.612 de 17 de novembro de 2011. Institui o Plano Nacional dos Direitos da Pessoa com deficiência - Plano viver sem limite. Diário Oficial da República Federativa do Brasil, Brasília, DF, 18 nov. 2011. Seção 1, p. 12.

CAVALCANTI, A.; GALVÃO, C.; MIRANDA, S. Mobilidade. In: CAVALCANTI, A.; GALVÃO, C. Terapia Ocupacional: fundamentação e prática. Rio de Janeiro: Guanabara Koogan, 2007. p. 427-434.

CAZEIRO, A. P. M. et al. A Terapia Ocupacional e as Atividades da Vida Diária, Atividades Instrumentais da Vida Diária e Tecnologia Assistiva. Fortaleza: ABRATO, 2011.

CLARK, F.; LAWLOR, M. C. The Making and Mattering of occupational science. In: CREPEAU, E. B.; COHN, E. S.; SCHELL, B. A. Willard \& Spackman: Occupational Therapy. 11th. ed. Philadelphia: Wolters Klover Lippincott Williams \& Wilkins, 2009. p. 02-14

CLARK, F.; WOOD, W.; LARSON, E. A. Ciência Ocupacional: legado da Terapia Ocupacional para o século XXI. In: NEISTADT, M. E.; CREPEAU, E. B. Willard \& Spackman: Terapia Ocupacional. Rio de Janeiro: Guanabara \& Koogan, 2002. p. 10-17.

CLARK, F.; ZEMKE, R. Occupational Science: The evolving discipline. Philadelphia: F.A. Davis, 1996.

COMPANHIA DE DESENVOLVIMENTO E ADMINISTRAÇÃO DA ÁREA METROPOLITANA
DE BELEM - CODEM. Cadastro Técnico Multifinalitário. Belém: CODEM, 2000.

FARIAS, N.; BUCHALLA, C. M. A. Classificação Internacional de Funcionalidade, Incapacidade e Saúde da Organizaçáo Mundial de Saúde: conceitos, usos e perspectivas. Revista Brasileira de Epidemiologia, São Paulo, v. 8, n. 2, jun. 2005. http://dx.doi.org/10.1590/ S1415-790X2005000200011

INSTITUTO BRASILEIRO DE GEOGRAFIA E ESTATÍSTICA - IBGE. Disponível em: <http://www. ibge.gov.br/cidadesat/topwindow.htm?1>. Acesso em: 29 nov. 2012.

LAW, M.; STEINWENDER, S.; LECLAIR, L. Occupation, health and well-being. Canadian Journal of Occupational Therapy, Toronto, v. 65, n. 2, p. 81-91, 1998.

LIKERT, R. A technique for the measurement of attitudes. Archives of Psychology, New York, v. 22, n. 140, p. $1-55,1932$.

MELLO, M. A. F. A Tecnologia Assistiva no Brasil. In: OLIVEIRA, A. I. A.; LOURENÇO, J. M. Q.; LOURENÇO, M. G.F. (Orgs.). Perspectivas da Tecnologia Assistiva no Brasil: pesquisa e prática. Belém: EdUEPA, 2008. p. 7-15.

ORGANIZAÇÃO MUNDIAL DE SAÚDE - OMS. Rumo a uma linguagem comum para Funcionalidade, Incapacidade e Sauide - CIF. Genebra: OMS, 2002. Disponível em: <http://www.fsp.usp.br/-cbcd/Material/ Guia_para_principiantes_CIF_cbcd.pdf $>$. Acesso: 12 dez. 2010.

ORGANIZAÇÃO MUNDIAL DE SAÚDE - OMS. Classificação Internacional de Funcionalidade, Incapacidade e Saúde: Classificação Detalhada com definiçóes. Genebra: OMS, 2003. Disponível em: <http://www.drealg.min-edu. pt/upload/docs/CIFIS.pdf>. Acesso: 12 dez. 2011.

ORGANIZAÇĀO MUNDIAL DE SAÚDE - OMS. Classificação Internacional de Funcionalidade, Incapacidade e Saúde - CIF. Tradução de Cassia Maria Buchalla. São Paulo: EdUSP, 2008.

RIO, V. D.; OliVeIRA, L. Percep̧ãa Ambiental a experiência brasileira. São Paulo: Studio Nobel, 1996.

ROZESTRATEN, R. J. A. Psicologia do Trânsito: conceitos e processos básicos. São Paulo: E.P.U., 1988.

SILVA, L. J. M.; EGLER, I. O estudo da percepção em espaços urbanos preservados. In: ENCONTRO DA ASSOCIAÇÃO NACIONAL DE PÓS GRADUAÇÃO E PESQUISA EM AMBIENTE E SOCIEDADE, 1., 2002, Indaiatuba. Anais... São Paulo: ANPPAS, 2002. Disponível em: <http://www.anppas.org.br/encontro_anual/encontro1/ $\mathrm{gt} /$ sustentabilidade_cidades/Luciene\%20de\%20Jesus $\% 20$ Maciel\%20da\%20Silva.pdf>. Acesso: 05 dez. 2011.

VASCONCELLOS, E. A. Transporte urbano, espaço e equidade: análise das políticas públicas. São Paulo: Annablume, 2001.

WILCOCK, A. A theory of the human need for occupation. Journal of Occupational Science, Adelaide, v. 1, n. 1, p. 17-24, 1993. 10.1080/14427591.1993.9686375 


\section{Contribuição dos Autores}

Éden Fernando Batista Ferreira: idealizador, concepção, elaboração, coleta e análise dos dados, redação do texto. Maisa Sales Gama Tobias: orientadora, concepção, elaboração e análise dos dados. Otávio Augusto de Araújo Costa Folha: redação de texto, análise dos dados, revisão.

\section{Notas}

${ }^{1}$ Trabalho referente a parte da pesquisa de mestrado no Programa de Pós-Graduação em Desenvolvimento e Meio Ambiente Urbano pela Universidade da Amazônia 